STUDI

FRANCESI

\section{Studi Francesi}

Rivista quadrimestrale fondata da Franco Simone

166 ( | | LVI) | 2012

Varia

\title{
Le Devenir-roman des "Mythologies" de Barthes, textes réunis et présentés par Guillaume Bellon et Pauline Vachaud
}

\section{Rachele Calisti}

\section{(2) OpenEdition \\ Journals}

\section{Edizione digitale}

URL: https://journals.openedition.org/studifrancesi/4805

DOI: $10.4000 /$ studifrancesi.4805

ISSN: 2421-5856

\section{Editore}

Rosenberg \& Sellier

\section{Edizione cartacea}

Data di pubblicazione: 1 avril 2012

Paginazione: 183

ISSN: 0039-2944

\section{Notizia bibliografica digitale}

Rachele Calisti, «Le Devenir-roman des "Mythologies" de Barthes, textes réunis et présentés par Guillaume Bellon et Pauline Vachaud», Studi Francesi [Online], 166 (I | LVI) | 2012, online dal 30 novembre 2015, consultato il 19 novembre 2021. URL: http://journals.openedition.org/studifrancesi/ 4805 ; DOI: https://doi.org/10.4000/studifrancesi.4805

Questo documento è stato generato automaticamente il 19 novembre 2021.

\section{c) (†) $\odot$}

Studi Francesi è distribuita con Licenza Creative Commons Attribuzione - Non commerciale - Non opere derivate 4.0 Internazionale. 


\title{
Le Devenir-roman des "Mythologies" de Barthes, textes réunis et présentés par Guillaume Bellon et Pauline Vachaud
}

\author{
Rachele Calisti
}

\section{NOTIZIA}

Le Devenir-roman des "Mythologies" de Barthes, textes réunis et présentés par Guillaume BELLON et Pauline VACHAUD, «Recherches \& Travaux», 77, 2010, pp. 151.

1 La critica ha spesso parlato di Roland Barthes definendolo di volta in volta un semiologo, un critico, uno strutturalista: una serie di appellativi nati dall'esigenza di classificare un autore poliedrico, eclettico ma che, in sostanza, si è sempre occupato principalmente della parola letteraria, analizzandola, criticandola e, infine, negli ultimi anni della sua vita, desiderando avvicinarsi ad essa in modo più concreto, da creatore, abbozzando un progetto per scrivere il suo romanzo e mettendosi così, al termine del suo percorso, nella posizione dell'homo faber che crea qualcosa, abolendo finalmente ogni discorso di discorso.

2 Gli autori degli articoli raccolti ne Le Devenir-roman des "Mythologies" de Barthes si pongono appunto l'obiettivo di rileggere Barthes partendo proprio dai suoi primi interventi pubblicati a partire dalla fine del 1952 sulla rivista «Lettres Nouvelles», dove il semiologo denuncia tutti i significati aggiunti alla parola primaria che esulano dal senso puro e semplice e sfuggono al valore letterale per divenire un'ideologia mistificatrice. Nella sua rubrica Petites Mythologies du mois, infatti, Barthes commenta, non senza ironia e sarcasmo, seguendo liberamente i suoi gusti e i suoi umori, soprattutto gli avvenimenti e costumi della media borghesia francese di allora, per 
smascherarne in realtà i tic e le abitudini spacciate come naturali ma sotto le quali, invece, si nascondono le menzogne e le ipocrisie della classe media.

Da Mythologies, tuttavia, come sottolineano Guillaume Bellon et Pauline Vachaud, non emerge solo un Barthes "flâneur de son époque» (p.6), prodotto del suo tempo, sferzatore marxista dei costumi borghesi. Alla verve persino violenta del discorso si mescola anche la nostalgia per un passato fatto di oggetti semplici e essenziali (la Citroën DS, la margarina Astra o il detergente Omo). In tal senso, già Mythologies, seguendo il ragionamento degli articoli della prima parte della raccolta, permette di scoprire un io di Barthes frutto in primo luogo di un progetto umano e intellettuale, con i suoi desideri e i suoi fallimenti e, soprattutto, inaccessibile a qualsiasi mitologia, lontano dalle aggressioni dalla parola convenzionale, dai clichés dell'epoca e dal buon senso delle opinioni standardizzate. Al contrario, Barthes si mette in una posizione di denuncia, ponendosi al di sopra dello stereotipo, rifuggendo la bêtise, il luogo comune, e lasciando così ancora spazio alla vera "parola" "déliée du carcan idéologique et déprise de la veine du commentaire» (p.11). Fin da questo suo primo lavoro appare dunque evidente come ben presto la letteratura diverrà per lui un'esigenza personale, il mezzo più efficace per scuotere il linguaggio delle mitologie, per imbrogliarlo $\mathrm{e}$, in tal modo, aggirarlo. Un inganno provvidenziale, un sottile espediente, un imbroglio bellissimo, come la definisce lui stesso nella celebre Leçon tenuta per la sua elezione alla Cattedra di Semiologia Letteraria del Collège de France.

4 La presente raccolta, dopo aver rintracciato il percorso teorico e pratico di Barthes dalle sue Mythologies al suo progetto di romanzo, nella seconda parte si interroga anche sulla possibilità che la parola barhesiana abbia indicato una strada, un «devenirlittérature» (p.139) che, partendo proprio da Mythologies, avrebbe successivamente ispirato alcune esperienze romanzesche contemporanee: la rielaborazione del mito in Jean-Philippe Touissant; il valore assunto dagli oggetti nell'opera di Jean Echenoz; l'importanza della demistificazione nei romanzi polizieschi di Fred Vargas o persino nei romanzi di fantascienza. Tali autori, attraverso una fedeltà alla forma, attuando il loro desiderio di scrittura più nella volontà di dire che nel significato stesso del loro linguaggio, sono riusciti a riattualizzare il discorso barthesiano. Davanti ad una parola ordinaria, retaggio di una cultura ormai logora, questi scrittori hanno dato vita a un'opera letteraria finalmente svincolata dal peso dell'eredità del passato, realizzando proprio quella riconciliazione tra uomini e reale, tra oggetto e parola sull'oggetto che Barthes auspicava attraverso le sue Mythologies e ricreando così quella che egli stesso ha definito nel corso di una sua intervista "una mitologia felice". 